\title{
Food limitation in epibenthic species in temperate intertidal systems in summer: analysis of 0-group plaice Pleuronectes platessa
}

\author{
Henk W. van der Veer $^{1, *}$, Vânia Freitas ${ }^{1,2}$, Joris Koot $^{1}{ }^{1}$ Johannes IJ. Witte $^{1}$, \\ Alain F. Zuur ${ }^{3,4}$ \\ ${ }^{1}$ Royal Netherlands Institute for Sea Research, PO Box 59, 1790 AB Den Burg Texel, The Netherlands \\ ${ }^{2}$ CIMAR/CIIMAR, Centro Interdisciplinar de Investigação Marinha e Ambiental, Universidade do Porto, \\ Rua dos Bragas 289, 4050-123 Porto, Portugal \\ ${ }^{3}$ Highland Statistics Ltd, 6 Laverock road, Newburgh, AB41 6FN Aberdeenshire, UK \\ ${ }^{4}$ Oceanlab, University of Aberdeen, Newburgh, AB41 6AA Aberdeenshire, UK
}

\begin{abstract}
The Balgzand intertidal is an important nursery area for early life stages of various epibenthic crustacean and fish species. Especially in summer, extremely high numbers of individuals occur. This study analyses whether these high densities in summer lead to food limitation using 0-group plaice Pleuronectes platessa L. as a model species. Between 1975 and 2007, this species was quantitatively monitored during $20 \mathrm{yr}$. The aim of this study is twofold: (1) a statistical analysis of field growth in relation to density, whereby negative density-dependent growth is considered as an indication of intraspecific competition, and (2) a comparison of observed field growth with predicted maximum growth according to the dynamic energy budget (DEB) model, to detect whether growth reduction occurs during the growing season as an indication of interspecies competition. The statistical analysis indicated no negative density-dependent growth during the whole growing season, suggesting the absence of intraspecies competition for food. The comparison of observed growth with DEB-predicted maximum growth showed that field growth was lower than the possible maximum, and that the difference increased over time until about the end of July, suggesting interspecies competition for food in summer. The stabilization in growth rate from July onwards might be related to a change in food quality: a shift from small bivalve siphons as main food items to larger tail tips of the lugworm Arenicola marina. These findings illustrate that not only food quantity but also food quality affects growth rates, at least in 0-group plaice.
\end{abstract}

KEY WORDS: Plaice · Pleuronectes platessa $\cdot$ Wadden Sea · Growth · Dynamic energy budget Intertidal $\cdot$ Food quantity $\cdot$ Food quality $\cdot$ Food limitation

\section{INTRODUCTION}

Shallow coastal systems are considered to be hostile environments, subject to strong variations in abiotic parameters that determine a relatively low species diversity (for overview see Goodall 1983). Regardless, shallow areas are used as nursery grounds by various epibenthic fish and crustacean species. Only a few species account for most of the numbers and biomass in shallow coastal systems, and these species are widely distributed (Haedrich 1983, Wolff 1983). This means that over a large latitudinal gradient, the same group of species is dominating. Along the European coast, the most abundant epibenthic species include the mobile invertebrates Crangon crangon and Carcinus maenas and the fishes Pomatoschistus minutus, 
P. microps, and the juvenile flatfishes Pleuronectes platessa, Platichthys flesus, Limanda limanda and Solea solea (Zijlstra 1972, Jensen \& Jensen 1985, Pihl 1985, Ansell et al. 1999, Amara 2003, Amara \& Paul 2003, Freitas et al. 2010a).

For those species, shallow coastal areas are typically important habitats as nursery grounds for early life stages due to presumed favourable conditions for growth and survival (Zijlstra 1972, Bergman et al. 1988). In general, juveniles arrive and settle in the intertidal with rising temperatures in spring and disappear with decreasing temperatures at the end of the growing season, emigrating to deeper waters. As a result, high densities (10s to 1000s of ind. $\mathrm{m}^{-2}$ ) of epibenthic consumers build up in these shallow areas in the course of the season. Since the various species have overlapping food spectra, these high numbers, and hence high biomass, have raised questions about their growth conditions, suggesting that food might be limited by either intra- and/or interspecies competition (Pihl 1985). For most species, growth is difficult to monitor due to more or less continuous settlement cohorts. The various flatfish species are an exception with, in general, a single cohort of settling larvae in spring. Therefore, flatfishes have become popular model species for the analysis of growth conditions in coastal nurseries, whereby the basic approach has been the comparison of observed field growth with predictions from a laboratory-based relationship of maximum growth in relation to water temperature (Zijlstra et al. 1982, van der Veer et al. 1991, 2001b, Jager et al. 1995). A potential problem with these growth models is that they are applicable over a restricted size range corresponding in most areas with the spring-early summer growth period only, although highest temperatures and biomasses occur in the summer-autumn period.

In most cases, the growth rate of juvenile flatfish in the field in spring and early summer was at a maximum level and only determined by temperature, as found for the Balgzand area in the western Dutch Wadden Sea, Loch Ewe, Scotland and Filey Bay, England (Zijlstra et al. 1982, van der Veer 1986), in Swedish bays (van der Veer et al. 1990), in the Dollard, Netherlands (Jager et al. 1995) and during part of the year in Port Erin Bay, Irish Sea (Nash et al. 1994). In some cases, negative density-dependent growth (Modin \& Pihl 1994) or reduced growth was observed, due to poor food conditions (van der Veer \& Witte 1993, Berghahn et al. 1995). Back-calculation of juvenile plaice growth based on otolith microstructure analysis showed an increase in growth rate from the 1950's onwards (Rijnsdorp \& van Leeuwen 1992), which was suggested to be related to an increase in availability of food in the coastal zone over that time period. However, for the period mid-June until September, ob- served growth rates of juvenile flatfish (plaice) in the field were much lower than the predicted maximum values, a phenomenon observed at Balgzand (Teal et al. 2008), the Dollard (Jager et al. 1995), the Irish Sea (Nash et al. 1994) as well as in northern Norway (Freitas et al. 2010a). This discrepancy between maximum possible and observed growth might suggest food limitation in summer due to the outburst of gobiids and crustaceans (Kuipers \& Dapper 1984), or it might be an experimental bias, since the plaice population from July onwards starts outgrowing the range where the maximum growth model can be applied (van der Veer et al. 2009). Solving the question of food and growth conditions in summer would require extensive laboratory experiments with larger-sized fish.

In this paper, an innovative approach that does not suffer from this size limitation, and which can be applied for the whole growing season, including the summer-autumn period, is used: the standard dynamic energy budget (DEB). The DEB is based on surfaceand volume-related processes and provides a framework describing the quantitative aspects of energy flows through an organism (Ross \& Nisbet 1990, Kooijman 2010). The energetics of a species is captured in a single model, where intraspecies variability (in size or length) is caused by differences in state variables (as a result of differences in environmental conditions, i.e. temperature, food), and interspecies variability is caused by differences in parameter values (Kooijman 2010). Applying the DEB model requires a set of species-specific parameters, which can be estimated from the result of experimental studies (van der Veer et al. 2006). For flatfishes, parameters were published in van der Veer et al. (2001a, 2009) and Freitas et al. (2010b). Once such a set is available, maximum possible growth (corresponding with a model situation of ad libitum food) can be estimated in relation to prevailing temperature conditions and compared with observed growth in the field. Subsequently, observed and predicted growth can be compared and used as an indicator of food conditions and hence of competition.

The present study analyses the food conditions in a temperate coastal nursery area in summer in the Balgzand intertidal area in the western Dutch Wadden Sea, where plaice Pleuronectes platessa is used as a model species. Between 1975 and 2007, 0-group plaice has been monitored quantitatively during 20 years. The aim of this study is twofold: (1) a statistical analysis of field growth in relation to density, whereby negative density-dependent growth is considered as an indication of intraspecific competition and (2) a comparison of observed field growth with predicted maximum growth according to the DEB model, to detect whether growth reduction occurs during the growing season as an indication of interspecies competition. 


\section{MATERIALS AND METHODS}

Field observations. Seasonal patterns of 0-group plaice were monitored in the Balgzand intertidal area in $20 \mathrm{yr}$ during the period 1975 to 2007. Sampling generally started in February and continued at frequent intervals ( 2 to 4 wk) until about October. During each survey, 9 transects distributed over the area were sampled, each consisting of 4 stations (Fig. 1). Sampling occurred within a $3 \mathrm{~h}$ period around high tide, during which the flatfish population is assumed to be randomly distributed over the area (Kuipers 1977). Hauls were taken during the day with a $1.9 \mathrm{~m}$ beam trawl with 1 tickler chain, a net mesh size of $5 \times 5 \mathrm{~mm}$, towed by a rubber dinghy with a $25 \mathrm{hp}$ outboard motor at a speed of $\sim 35 \mathrm{~m} \mathrm{~min}^{-1}$ (Riley \& Corlett 1966). Location of the hauls was initially established by fixed poles at the beginning of each transect and later by GPS. Exact length of the hauls was assessed with a meter wheel fitted to the trawl. Occasionally, some stations could not be sampled due to extreme weather conditions (wind stress, reduced water depths). During all cruises, except for 1975 and 1976, bottom water temperature measurements were taken to the nearest ${ }^{\circ} \mathrm{C}$. For 1975 and 1976, water temperature was estimated from a nearby station, Marsdiep (Fig. 1), based on a linear regression model for the mean monthly Marsdiep temperatures for 1977 to 2002 (van Aken 2003) and those

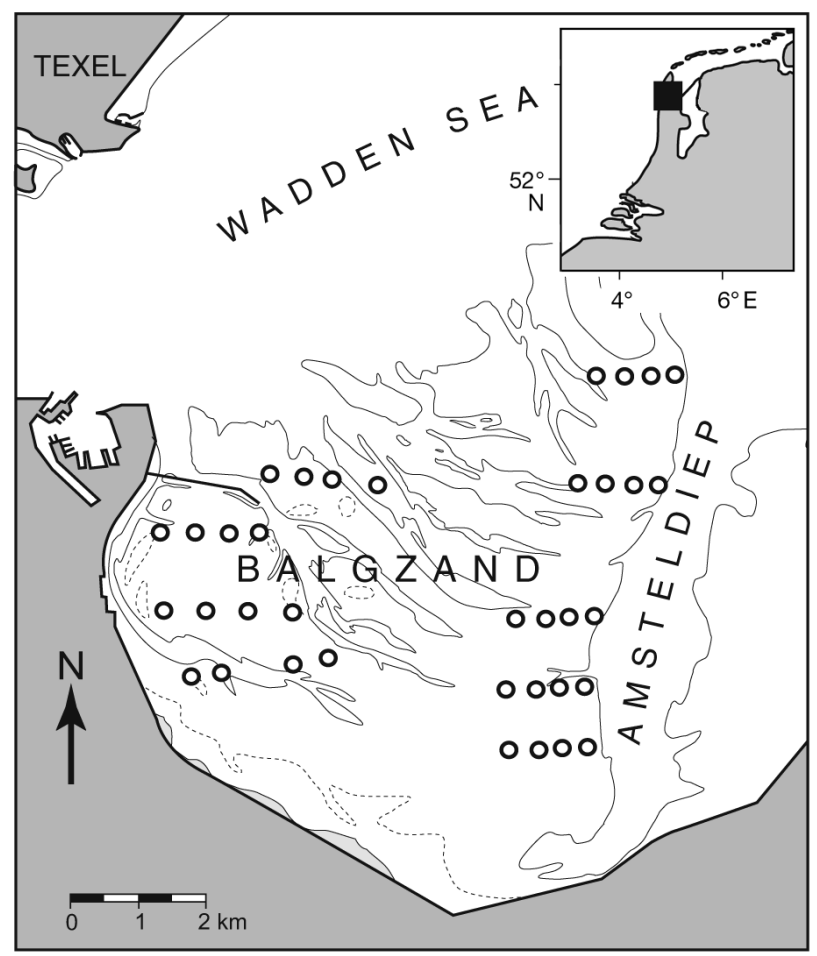

Fig. 1. The Balgzand intertidal area in the western Dutch Wadden Sea. Each transect consisted of 4 hauls (O). Thin lines indicate the low water mark, dashed lines the high water mark of the Balgzand area. The regression model $\left(\mathrm{T}_{\text {Marsdiep }}=\right.$ $1.02 \times \mathrm{T}_{\text {Balgzand }}+0.36$ ) indicated a strong relationship $\left(\mathrm{R}^{2}=0.95, \mathrm{n}=228, \mathrm{p}<0.01\right)$ between temperature at high water at Balgzand $\left(\mathrm{T}_{\text {Balgzand, }}{ }^{\circ} \mathrm{C}\right)$ with that of the nearby Marsdiep station $\left(\mathrm{T}_{\text {Marsdiep }}{ }^{\circ} \mathrm{C}\right)$.

Catches were immediately stored in a $4 \%$ formalin solution (until 1990) or deep-frozen (from 1991 onwards) and sorted within a few days. The 0-group plaice present in the catches were preserved in $70 \%$ ethanol and, within a few days, total length (TL) was measured to the nearest $\mathrm{mm}$. No correction for shrinkage was applied. For each haul, numbers caught were corrected for size-selective mesh and catch efficiency after Kuipers (1975) and Dapper (1978) and then converted into ind. per $1000 \mathrm{~m}^{2}$ (ind. $\left[10^{3} \mathrm{~m}^{2}\right]^{-1}$ ). The arithmetic mean density and mean size in $\mathrm{TL}$, considering all stations sampled during a cruise, was taken as an index of the population (cf. Kuipers 1977, Zijlstra et al. 1982).

To eliminate a bias in growth rate estimates due to settlement of larvae in spring, data analysis was restricted to the period from peak settlement in May, which generally coincided with a peak in maximum abundance, and until the end of September, to limit the potential bias introduced by autumn emigration of juveniles. Daily growth in length $\left(\mathrm{d} L_{i} \mathrm{~cm} \mathrm{~d}^{-1}\right)$ was estimated from the changes in population mean TL between consecutive sampling periods (cf. Zijlstra et al. 1982, van der Veer 1986).

DEB model. The DEB theory (Kooijman 2010) describes energy flows through an animal (Fig. 2) under conditions in which food densities and temperatures vary. Food uptake is assumed to follow a functional response relationship with food density. In line with observations on juvenile flounder (Kiorbøe 1978, Mattila \& Bonsdorff 1998), a Holling type-II hyperbolic function seems to be sufficient to quantitatively reproduce ingestion rate in plaice. Environmental food conditions are described in the form of a scaled functional response $f$, where 0 reflects starvation, and 1 optimal food conditions (feeding ad libitum). Food uptake is proportional to organism surface area and converted into reserves with a constant efficiency. Mobilized reserves are allocated to growth, to maintenance of existing body tissues (somatic and gonadal) and to maturation or reproduction. A fixed fraction ( $\kappa$ rule) of reserve is allocated to growth plus somatic maintenance while the remaining fraction $(1-\kappa)$ is allocated to maturity maintenance plus maturation and/or reproduction. Maintenance has priority over growth, and hence, growth ceases when all reserve that is allocated to somatic maintenance plus growth is required for somatic maintenance. The mobilization rate of reserve is proportional to the ratio of reserve density (i.e. the ratio of reserve and body structure) and volumetric length (the cubic root of structure's volume), and the 


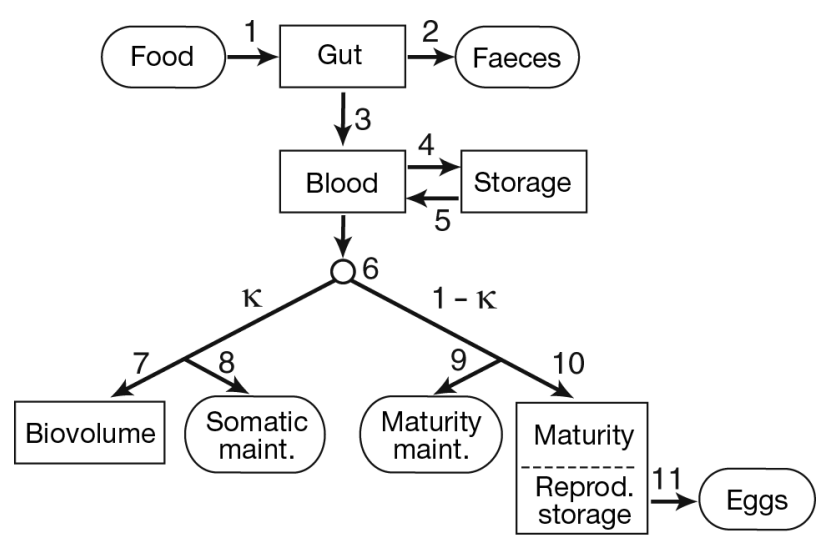

Fig. 2. Energy flow through an organism in the DEB model, after van Haren (1995). Rates = 1: ingestion (uptake), 2: defecation, 3: assimilation, 4: demobilization of energy into reserves, 5: mobilization of energy from reserves, 6: utilization, 7: growth, 8: maintenance, 9: maturation maintenance, 10: maturation, 11: reproduction. Rounded boxes: sources or sinks, Squares: state variables. $\kappa$ and $1-\kappa$ : fractions of energy allocated to, respectively, growth + somatic maintenance and maturity maintenance + maturation and/or reproduction

energy costs of maintenance are proportional to the volume of the structure.

With a set of species-specific parameters, the DEB model can be applied for all combinations of fish size, food conditions and temperature. At constant food densities, the reserves are in equilibrium with the environment and consequently growth of structural biovolume represents a weighted difference between surface area and volume, which corresponds with the von Bertalanffy growth curve (Kooijman 2010):

$$
\frac{d}{d t} L=\dot{r}_{\mathrm{B}}\left(L_{\infty}-L\right)
$$

The parameters $L_{\infty}$ (ultimate size; $\mathrm{cm}$ ) and $\dot{r}_{\mathrm{B}}$ (von Bertalanffy growth rate constant, $\mathrm{d}^{-1}$ ) can thus be written as a combination of DEB parameters:

$$
\begin{gathered}
L_{\infty}=f \frac{L_{\mathrm{m}}}{\delta_{\mathrm{M}}}=f \frac{\dot{\mathrm{v}}}{g \dot{k}_{\mathrm{M}} \delta_{\mathrm{M}}} \\
\dot{r}_{\mathrm{B}}=\frac{1}{3 / \dot{\mathrm{k}}_{\mathrm{M}}+3 f L_{\mathrm{m}} / \dot{v}}=\frac{\dot{k}_{\mathrm{M}} / 3}{1+f / g}
\end{gathered}
$$

where $f$ is the scaled functional response (dimensionless), $\delta_{\mathrm{M}}$ is the shape coefficient $(-), L_{\mathrm{m}}$ the maximum volumetric length an individual can reach $(\mathrm{cm}), \dot{v}$ is the energy conductance $\left(\mathrm{cm} \mathrm{d}^{-1}\right)$, a parameter related to reserve dynamics, $g$ is the investment ratio (-) that stands for the costs of new biovolume relative to the maximum potentially available energy for growth and maintenance, and $\dot{k}_{\mathrm{M}}$ is the maintenance rate coefficient $\left(\mathrm{d}^{-1}\right)$, which stands for the ratio of somatic maintenance costs to structure. This means that the DEB theory gives a physiological interpretation to the von Bertalanffy parameters (see Kooijman 2010). Justification for applying Eq. (1) for plaice is the fact that plaice growth follows von Bertalanffy growth (van der Veer et al. 2001a).

Changes in food conditions $(f)$ are expected to affect both $L_{\infty}$ and $\dot{r}_{B}$, while temperature conditions affect $\dot{r}_{B}$ only due to the temperature dependence of physiological rates. In the DEB model, the temperature effect is based on an Arrhenius type relation that describes the rates at ambient temperature, $\dot{k}(T)$, as follows:

$$
\dot{k}(T)=k_{1} \mathrm{e}^{\left(\frac{T_{\mathrm{A}}}{T_{1}}-\frac{T_{\mathrm{A}}}{T}\right)} \cdot \frac{1+\mathrm{e}^{\left(\frac{T_{\mathrm{AL}}}{T_{1}}-\frac{T_{\mathrm{AL}}}{T_{\mathrm{L}}}\right)}+\mathrm{e}^{\left(\frac{T_{\mathrm{AH}}}{T_{\mathrm{H}}}-\frac{T_{\mathrm{AH}}}{T_{1}}\right)}}{1+\mathrm{e}^{\left(\frac{T_{\mathrm{AL}}}{T}-\frac{T_{\mathrm{AL}}}{T_{\mathrm{L}}}\right)}+\mathrm{e}^{\left(\frac{T_{\mathrm{AH}}}{T_{\mathrm{H}}}-\frac{T_{\mathrm{AH}}}{T}\right)}}
$$

where $T$ is absolute temperature $(\mathrm{K}), T_{\mathrm{AL}}$ and $T_{\mathrm{AH}}$ are Arrhenius temperatures $(\mathrm{K})$ for the rate of decrease at the lower $\left(T_{\mathrm{L}}\right)$ and upper $\left(T_{\mathrm{H}}\right)$ boundaries, respectively. $T_{1}$ is the reference temperature $(k), T_{\mathrm{A}}$ the Arrhenius temperature $(k)$, and $k_{1}$ is the rate at the reference temperature.

Data analysis. To test for intraspecies competition, the variability in the observed growth rate $\mathrm{d} L\left(\mathrm{~cm} \mathrm{~d}^{-1}\right)$ between time $t=i$ and $t=i+1$ was analysed as a function of mean population length, density and water temperature at $t=i$. A significant negative relationship of population density with growth was considered as an indication of intraspecies competition.

Secondly, for all field observations, $\mathrm{d} L$ was expressed as the ratio of maximum possible growth predicted by the DEB model. Differences in the ratio over time, especially a decrease in summer onwards was considered as an indication of interspecies competition.

Field observations: Prior to the statistical analysis of the field growth rates, a data exploration was carried out following the protocol described in Zuur et al. (2010). Potential outliers were checked using Cleveland dotplots, and multi-panel scatterplots were used to identify the type of relationships between variables (e.g. linear versus non-linear) and the presence of collinearity among covariates.

To investigate the relationships of field growth rates $(D L)$ with temperature, plaice mean length and population density, a linear regression model was applied:

$$
\begin{aligned}
D L_{i j}= & \alpha+\beta_{1} \times \text { Length }_{i j}+\beta_{2} \times \text { Density }_{i j}+ \\
& \beta_{3} \times \text { Temperature }_{i j}+\varepsilon_{i j}
\end{aligned}
$$

where $D L_{\mathrm{ij}}$ is the growth rate $\left(\mathrm{cm} \mathrm{d}^{-1}\right)$ between sampling day $j$ and $j+1$ in year $i$, Length $(\mathrm{cm})$, Density (ind. $\left[10^{3} \mathrm{~m}^{2}\right]^{-1}$ ) and Temperature $\left({ }^{\circ} \mathrm{C}\right.$ ) are covariates, and $\varepsilon_{i j}$ is the residual. Model validation showed that the residuals exhibited some heterogeneity (a decrease in variation along day of the year) and presented a year effect. To avoid the violation of hetero- 
geneity and dependence problems, linear mixed effects models were applied (Zuur et al. 2009) in which year was used as random intercept:

$$
\begin{aligned}
D L_{i j}= & \alpha+\beta_{1} \times \text { Length }_{i j}+\beta_{2} \times \text { Density }_{i j}+ \\
& \beta_{3} \times \text { Temperature }_{i j}+a_{i}+\varepsilon_{i j}
\end{aligned}
$$

The random intercept $a_{i}$ is assumed to be normally

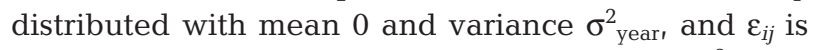
normally distributed with mean 0 and variance $\sigma_{\varepsilon}^{2}$. The random intercept $a_{i}$ is imposing a temporal correlation structure on the observations within a year, namely the so-called compound symmetric correlation (Pinheiro \& Bates 2000). This means that the correlation between 2 observations from the same year is equal to $\rho$, where $\rho$ (also called the intra-class correlation [ICC]) is estimated by:

$$
\rho=\frac{\sigma_{\text {year }}^{2}}{\sigma_{\text {year }}^{2}+\sigma_{\varepsilon}^{2}}
$$

Because the observed time series within a year are short, irregularly spaced, and unbalanced over the years, a more sophisticated correlation structure was not considered.

We also considered smoothing equivalents of the model in Eq. (6). In such additive mixed effects models (AMMs), the parametric terms are replaced by smoothing splines, resulting in:

$$
\begin{aligned}
D L_{i j}= & f\left(\text { Length }_{i j}\right)+f\left(\text { Density }_{i j}\right)+ \\
& f\left(\text { Temperature }_{i j}\right)+a_{i}+\varepsilon_{i j}
\end{aligned}
$$

Cross-validation was used to estimate the optimal amount of smoothing for each smoother.
All calculations were carried out in $\mathrm{R}$ version 2.9.1 ( $\mathrm{R}$ Development Core Team 2009). Linear mixed effects models were fitted using the nlme package (Pinheiro et al. 2009) and the AMMs using the mgcv package (Wood 2006).

DEB predictions: Growth rates predicted by the DEB model under constant and maximum possible food conditions $(f=1)$ at various temperatures were estimated by Eqs. (1) \& (4). DEB parameter values were taken from van der Veer et al. (2009) and Freitas et al. (2010b). Due to differences in food intake and in energy participation, males and females have different parameter sets (Table 1), and hence, growth characteristics (Freitas et al. 2010b). Therefore, maximum growth predictions in relation to temperature were made for both sexes separately.

The ratio of observed and DEB predicted maximum growth rates was estimated and analyzed over time. To help visualize patterns, a smoothing curve was added using the LOESS function in R (R Development Core Team 2009).

\section{RESULTS}

The seasonal patterns in 0-group plaice density, mean length, water temperature and daily growth rate were rather consistent over the years (Fig. 3). Maximum numbers occurred by the end of April and beginning of May, followed by a reduction and a stabilization from about July onwards. Over this period of time, mean length increased continuously

Table 1. Dynamic energy budget (DEB) model parameters for male and female plaice Pleuronectes platessa at $283 \mathrm{~K}\left(10^{\circ} \mathrm{C}\right)$. Parameters after van der Veer et al. (2009) and Freitas et al. (2010b). For details on the notation used see Kooijman et al. (2010)

\begin{tabular}{|lclcc|}
\hline Symbol & Units & Interpretation & Male plaice & Female plaice \\
\hline$T_{\mathrm{A}}$ & $\mathrm{K}$ & Arrhenius temperature & 7000 & 7000 \\
$\left\{\dot{p}_{\mathrm{Am}}\right\}$ & $\mathrm{J} \mathrm{cm}^{-2} \mathrm{~d}^{-1}$ & Maximum surface area specific assimilation rate & 234 & 390 \\
{$\left[\dot{p}_{\mathrm{M}}\right]$} & $\mathrm{J} \mathrm{cm}^{-3} \mathrm{~d}^{-1}$ & Volume specific maintenance costs & 19.4 & 19.4 \\
{$\left[E_{\mathrm{M}}\right]$} & $\mathrm{J} \mathrm{cm}^{-3}$ & Maximum storage density & 1500 & 2500 \\
{$\left[E_{\mathrm{G}}\right]$} & $\mathrm{J} \mathrm{cm}^{-3}$ & Volume-specific costs of growth & 5600 & 5600 \\
$\kappa$ & - & Fraction of utilized energy spent on maintenance plus growth & 0.95 & 0.85 \\
$\delta_{\mathrm{M}}$ & - & Shape coefficient & 0.219 & 0.219 \\
$\dot{v}$ & $\mathrm{~cm} \mathrm{~d}-1$ & Energy conductance & 0.156 & 0.156 \\
$\dot{k}_{\mathrm{M}}=\left[\dot{p}_{\mathrm{M}}\right] /\left[E_{\mathrm{G}}\right]$ & $\mathrm{d}^{-1}$ & Maintenance rate constant & 0.0035 & 0.0035 \\
$g=\left[E_{\mathrm{G}}\right] / \kappa\left[E_{\mathrm{M}}\right]$ & - & Investment ratio & 3.930 & 2.635 \\
$L_{\mathrm{m}}=k\left\{\dot{p}_{\mathrm{Am}}\right\} /\left[\dot{p}_{\mathrm{M}}\right]$ & $\mathrm{cm}$ & Maximum volumetric length & 52 & 78 \\
$T_{\mathrm{L}}$ & $\mathrm{K}$ & Lower boundary of tolerance range & 277 & 277 \\
$T_{\mathrm{H}}$ & $\mathrm{K}$ & Upper boundary of tolerance range & 295 & 295 \\
$T_{\mathrm{AL}}$ & $\mathrm{K}$ & Rate of decrease at lower boundary & 50000 & 50000 \\
$T_{\mathrm{AH}}$ & $\mathrm{K}$ & Rate of decrease at upper boundary & 75000 & 75000 \\
\hline
\end{tabular}


from $1.5 \mathrm{~cm}$ at settlement in spring to a size of around 9 to $10 \mathrm{~cm}$ at the beginning of autumn. Water temperature showed a clear seasonal pattern with a maximum of $\sim 20^{\circ} \mathrm{C}$ in July and August. Mean growth rate decreased from 0.08 in spring to $0.02 \mathrm{~cm}$ $\mathrm{d}^{-1}$ in autumn.

\section{Field observations}

A multi-panel plot showed similar patterns for the various years where a steady decrease in growth rates was associated with an increase in mean length, a decrease in population density and a domeshaped curve in water temperature (Fig. 4). In some years, the pattern in population density and water temperature was irregular. Cleveland dotplots (not shown) of the various variables did not indicate outliers in any of the variables except for population density. Four observations were considerably larger
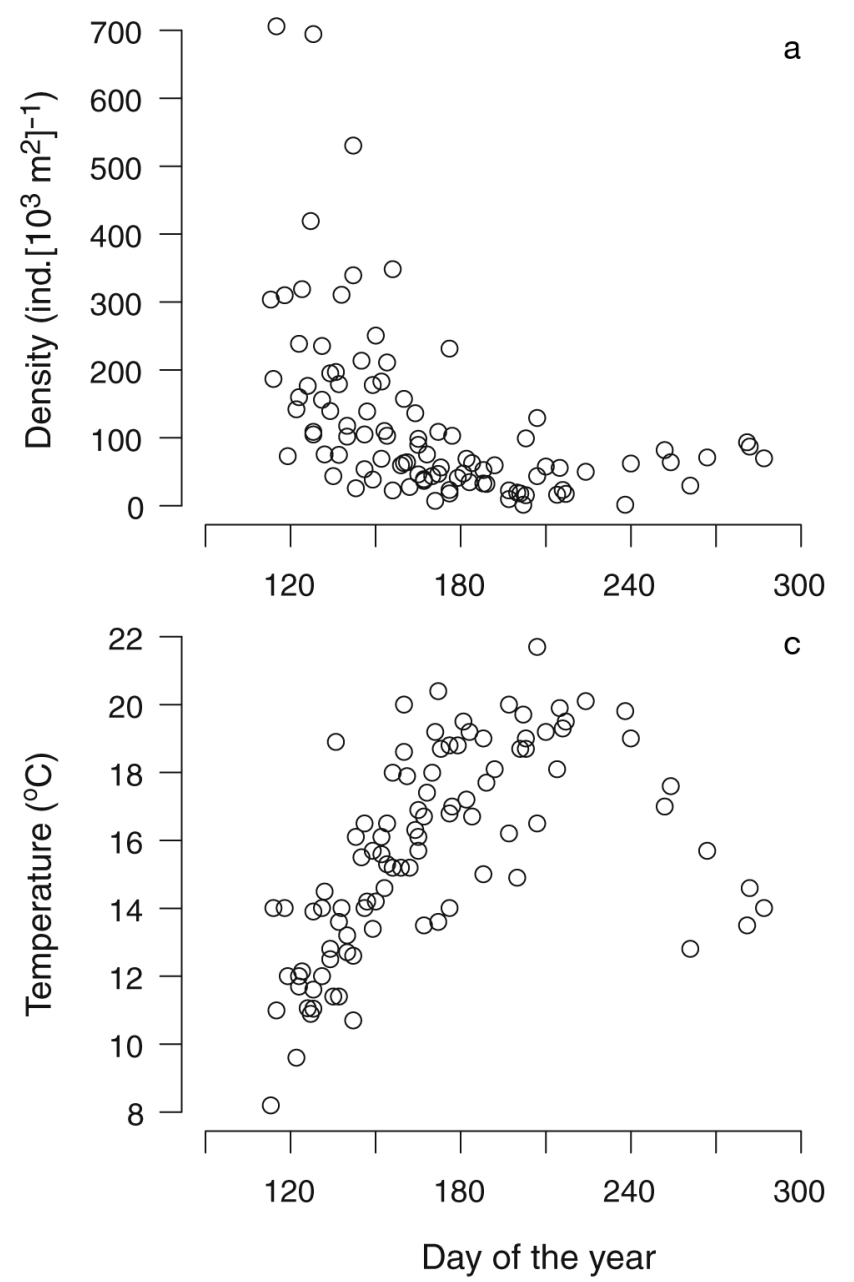

than the rest, 3 from 1996 and 1 from 2001 (Fig. 5). Instead of transforming the data, 2 statistical analyses were conducted: one where the extreme cases were omitted and another containing all data. Multi-panel scatterplots suggested a slightly non-linear relationship between growth rate and mean length as well as some degree of collinearity between the covariates (Fig. 5). To deal with collinearity, one factor had to be dropped and temperature was chosen as it had a less clear relationship with growth rate.

The linear mixed effects model (Eq. 5), in which mean length and population density were used as the remaining covariates, showed that only mean length was significant. However, a plot of residuals against mean length revealed a slight non-linear pattern (see also scatterplots of Fig. 5). Therefore, additive mixed modelling was applied (Eq. 8), starting with mean length and density as covariates. Cross-validation indicated that density could be fitted as a linear term, but since it did not have a significant effect at the $5 \%$ level,
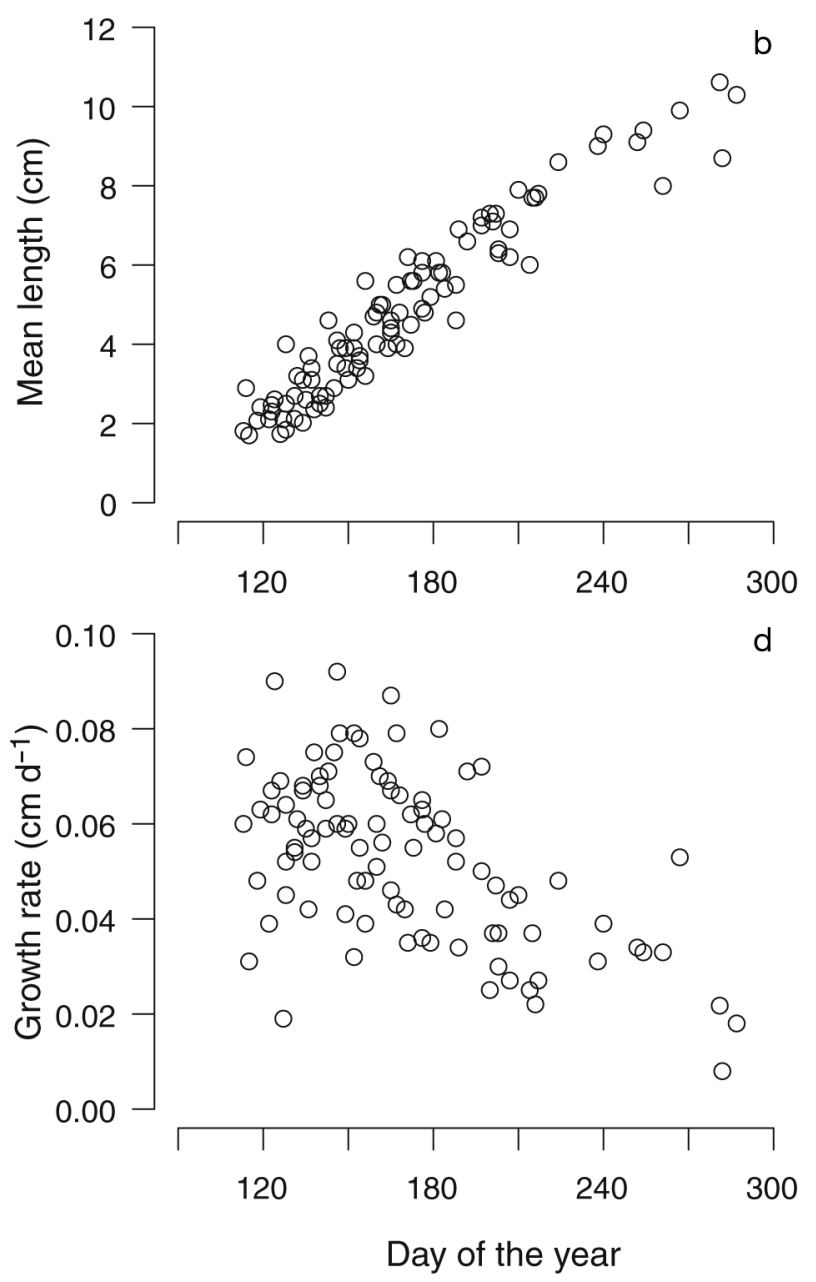

Fig. 3. Pleuronectes platessa. Seasonal patterns in 0-group plaice (a) density (ind. $\left[10^{3} \mathrm{~m}^{2}\right]^{-1}$ ), (b) mean length (cm), (c) water temperature $\left({ }^{\circ} \mathrm{C}\right)$, and $(\mathrm{d})$ growth rate $\left(\mathrm{cm} \mathrm{d}^{-1}\right)$ at Balgzand for the period 1975-2007. Circles indicate observed values for various years together 


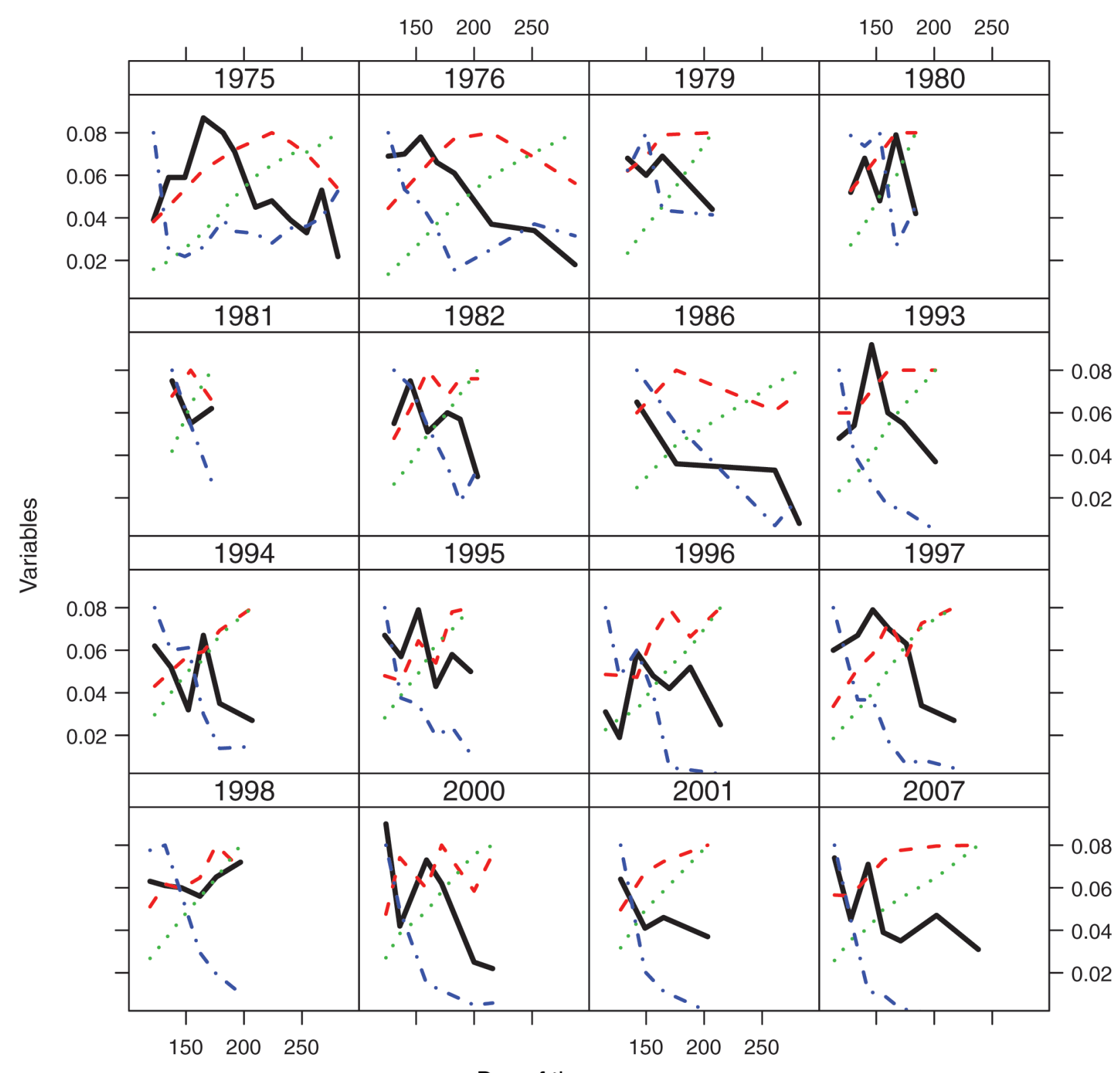

Day of the year

Fig. 4. Pleuronectes platessa. Time series plot of 0-group growth rates (thick black solid line), temperature (dashed red line), mean length (dotted green line) and density (dash-dotted blue line). The y-scale for growth rates and all variables were rescaled to fit between 0 and 0.08

it was removed from the model. Therefore, the optimal final model was given by:

$$
D L_{i j}=f\left(\text { Length }_{i j}\right)
$$

with an ICC (Eq. 7) of 0.175, meaning that the correlation between any 2 observations from the same year was $17.5 \%$.

The need of a random intercept was tested by fitting 2 AMM models, one with and another without a random intercept, and applying a likelihood ratio test while correcting for testing on the boundary (Zuur et al. 2009). Results gave $\chi^{2}=3.289(\mathrm{df}=1, \mathrm{p}<0.05)$, indicating that the best model was the one including the random intercept. The estimated df for the smoother of mean length was 2.35 , and the resulting smoother was slightly non-linear (Fig. 6). The residuals of the model were homogeneous and approximately normally distributed. The statistical analysis including extreme cases for density did not deviate from these results and similar conclusions were obtained: a negative and slightly non-linear length effect on growth rate and no impact from density. 

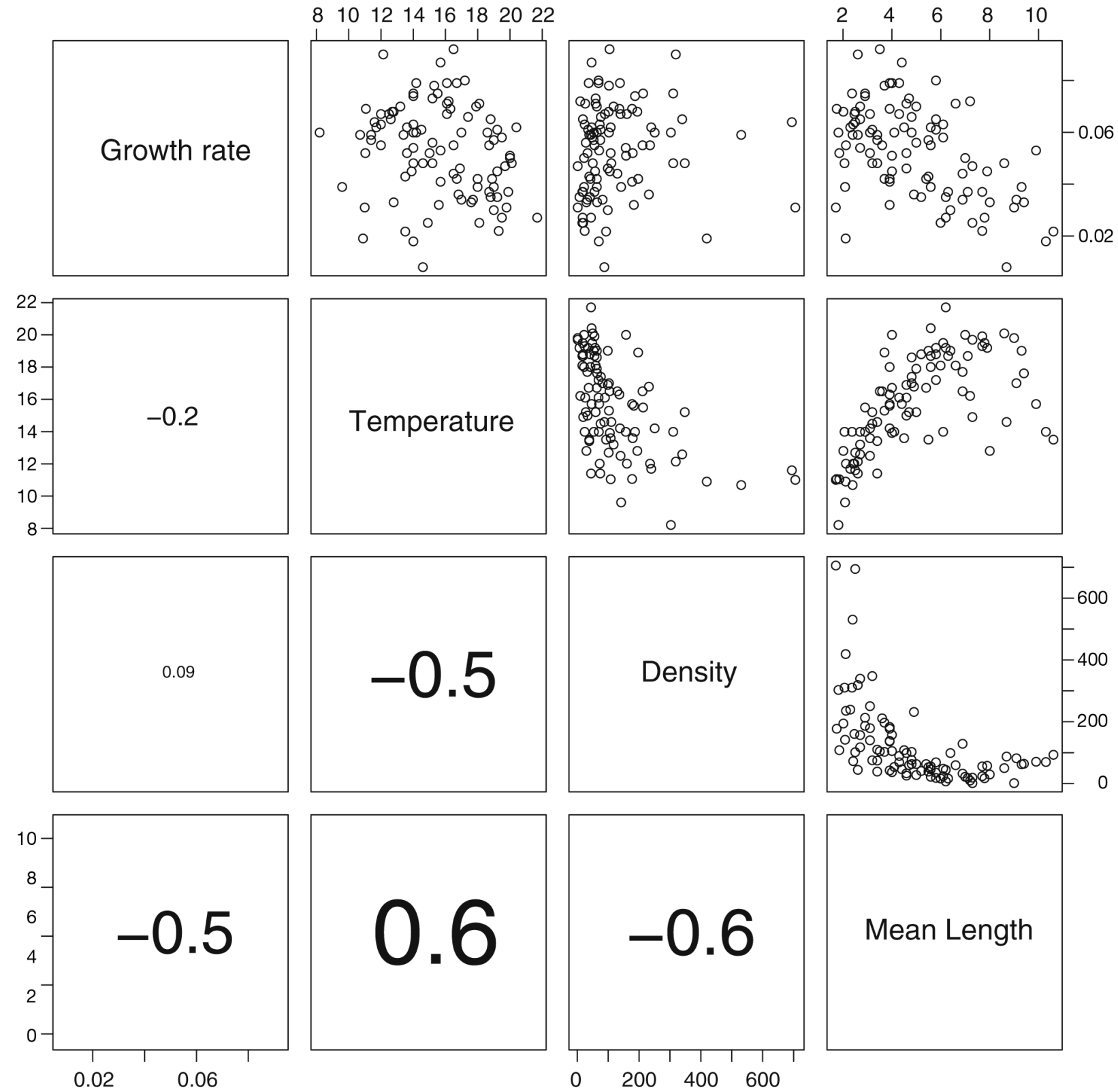

Fig. 5. Pleuronectes platessa. Multipanel scatterplots between 0 -group growth rate $\left(\mathrm{cm} \mathrm{d}^{-1}\right)$ and each covariate. Pearson correlation values: size of characters is proportional to the correlation found

\section{DEB predictions}

DEB parameters for males and females are listed in Table 1 . At $10^{\circ} \mathrm{C}$, the growth rates of female and male plaice amounted to 0.065 and $0.048 \mathrm{~cm} \mathrm{~d}^{-1}$, respectively. After incorporating the temperature effect, DEB model predictions showed a similar pattern as in the experimental observations by Fonds et al. (1992), and similar ranges in the case of males (Fig. 7a). Furthermore, growth rate was negatively related to fish length (Fig. 7b).

In relation to predicted maximum DEB growth rates, observed growth rates showed a decrease over time and were generally lower for both males and females (Fig. 8), although the differences were stronger for females for which the DEB model predicted higher growth rates. Overall, the discrepancy increased over time, stabilizing from about Day 240 onwards (Fig 8).

\section{DISCUSSION}

The diet of juvenile plaice consists of a variety of macroozoobenthic prey items, including both polychaetes and bivalves, varying from body parts (siphon 


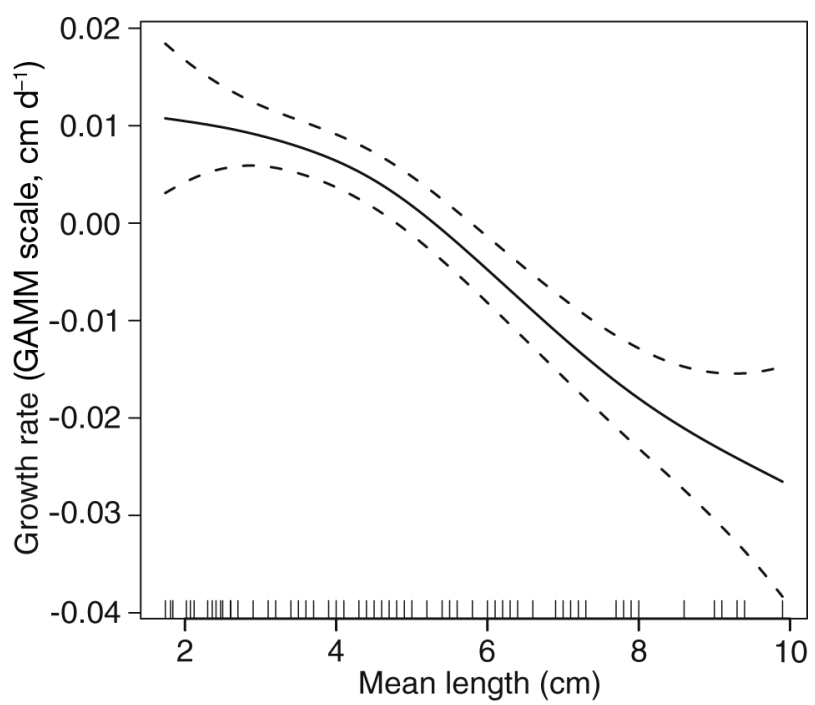

Fig. 6. Pleuronectes platessa. Estimated smoothing function obtained from a generalized additive mixed model (GAMM) for 0-group growth rate as a function of mean fish length. Mean length (vertical lines; $\mathrm{cm}$ ) vs. contribution of the smoother to the fitted values of growth rate $\left(\mathrm{cm} \mathrm{d}^{-1}\right)$. Solid curve: cubic smoothing spline fit for the continuous covariate, Dashed lines: 95\% confidence bands around the fit. The smoother df (2.35) were calculated with cross-validation

tips, tail tips) to whole individuals (Kuipers 1977, De Vlas 1979). Plaice is an opportunistic feeder whose diet generally reflects the composition of the benthic fauna (De Vlas 1979) and is in competition with other epibenthic species that also prey upon macrozoobenthos such as other juvenile flatfishes Platichthys flesus, Limanda limanda and Solea solea, fish species Pomatoschistus minutus, P. microps, and mobile invertebrates Crangon crangon and Carcinus maenas (Kühl \& Kuipers 1983). Since 0-group plaice consists of a single settlement cohort, it was selected as a model species. With respect to location, the Balgzand intertidal is an isolated important nursery area in the Dutch Wadden Sea, allowing quantitative studies in plaice (Zijlstra et al. 1982, van der Veer \& Witte 1999), as well as in other flatfish species (van der Veer et al. 1991, 2001b, Bolle et al. 1994), gobiids (van Beek 1976) and crustaceans (Kuipers \& Dapper 1981, 1984). Moreover, especially in summer, extremely high numbers of early life stages of various epibenthic species occur in the area, making the Balgzand intertidal a suitable area for studies on food competition.

\section{Intraspecies competition}

The statistical analysis to test whether growth is (negatively) density-dependent is straightforward. Since plaice growth depends not only on prevailing water
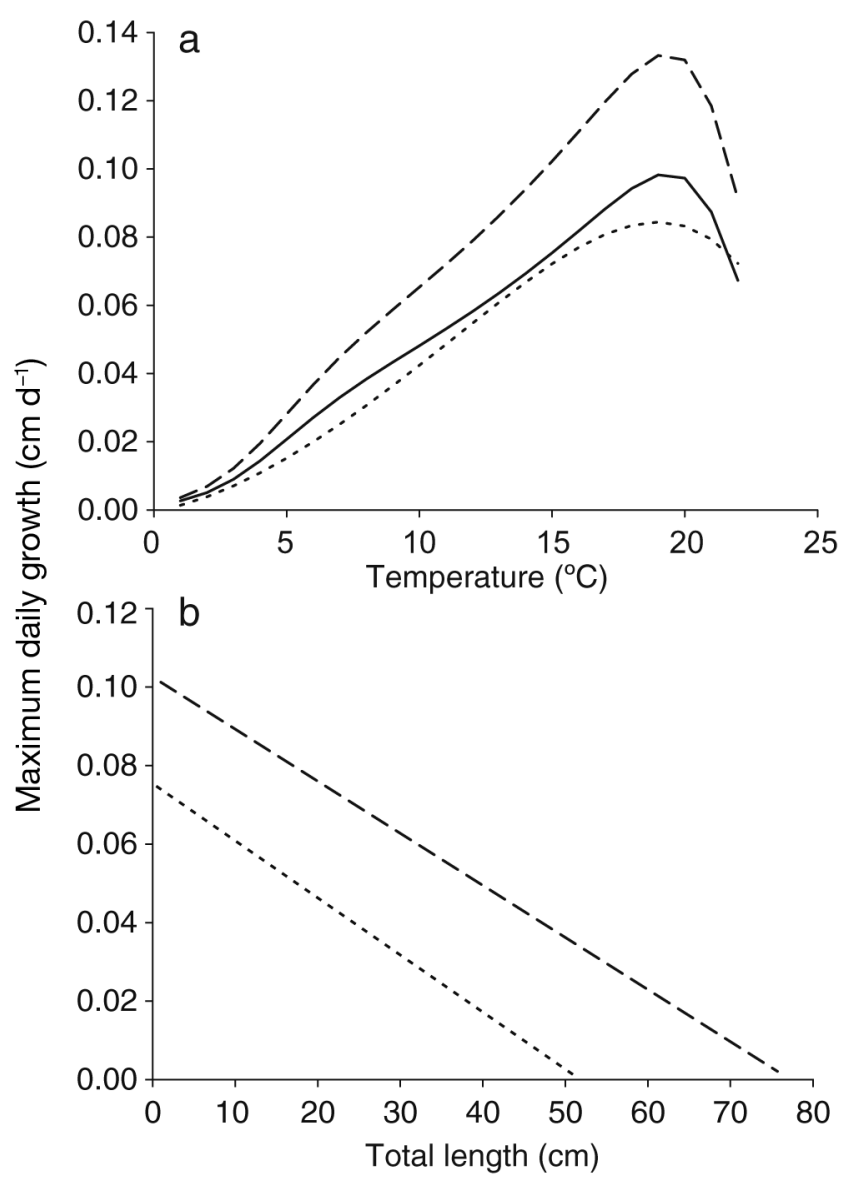

Fig. 7 Pleuronectes platessa. Maximum daily growth $\left(\mathrm{cm} \mathrm{d}^{-1}\right)$ of 0 -group plaice under optimal constant food conditions $(f=1)$ according to the DEB model for females (dashed line) and males (dotted line) in relation to (a) water temperature $\left({ }^{\circ} \mathrm{C}\right)$ together with Fonds et al.'s (1992) laboratory-derived growth model (solid line) and (b) total length $(\mathrm{cm})$

temperature (Fonds et al. 1992) but also on fish size (van der Veer et al. 2009), these 2 factors had to be included in the statistical model of field growth. However, this was impossible due to the collinearity between temperature and plaice length. One factor had to be dropped and temperature was selected since it had a less clear relationship with growth rates. The consequence is that the statistical model cannot be applied for growth predictions in other areas with different temperature regimes. However, this was not the aim of this study. The observed inverse relationship between growth and mean length is according to expectations.

One problem concerned the variability in the data especially caused by the extremely high peak densities of the 1996 year class. An option would have been to transform this variable, but it would have resulted in reduced resolution between the individual observations. Therefore, no transformation was applied and instead 2 

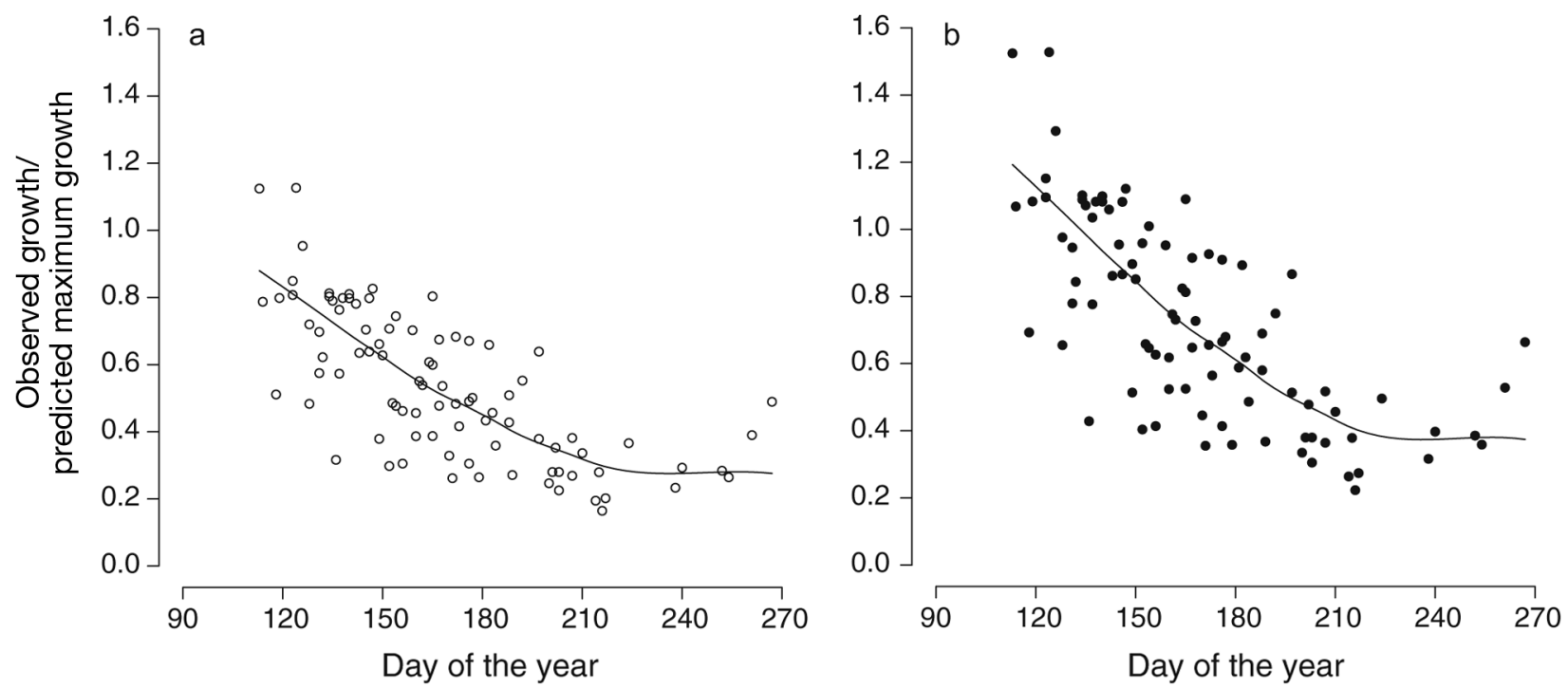

Fig. 8. Pleuronectes platessa. Seasonal pattern in the ratio between observed growth and predicted maximum growth (DEB model) for (a) female and (b) male 0-group plaice. Smoothing curve added using LOESS function in R to capture patterns over time. All years together

different analyses were run: one excluding the extreme cases and another including them. The fact that the results of both analyses did not deviate justified, in our opinion, the decision of not transforming the data.

The autocorrelation in the data set is another aspect that should be kept in mind. Since the estimates are based on the differences between 2 successive observations, a biased sample immediately introduces variability in successive estimates. In the beginning of the season, just-settled plaice redistribute from the settlement areas over the Balgzand area (van der Veer 1986) and this might have introduced some variability in the estimates. In fact, the correlation between any 2 observations from the same year was about $18 \%$.

The statistical analysis did not indicate a relationship with density, suggesting the absence of intraspecies competition for food during the whole growing season including the summer period. These findings are in line with previous analyses of population growth in the Dutch Wadden Sea (van der Veer \& Witte 1993). More detailed analyses based on otolith microstructure analysis of individual fish showed that only in exceptional cases, negative density-dependent growth could be observed: in small Swedish bays at densities of several ind. $\mathrm{m}^{-2}$ (Modin \& Pihl 1994). These densities are far above those occurring at the Balgzand intertidal: only in exceptional cases and for a short period during settlement, densities $>1$ ind. $\mathrm{m}^{-2}$ were observed (van der Veer et al. 2000) and, during the growing season, are in general an order of magnitude lower. The absence of intraspecies competition for food at Balgzand is in support of the 'maximum growth/optimal food conditions' theory (Karakiri et al. 1991).

\section{Interspecies competition}

In line with previous research, the analysis of interspecies food competition was based on whether growth is maximal or reduced compared with a predictive maximum growth model. Different from previous studies, the maximum growth model of Fonds et al. (1992) was replaced by a DEB model (Kooijman 2010) and instead of comparisons of absolute growth rates, a ratio was introduced. The main reason for using the DEB approach was that it allowed an estimate of maximum possible growth rates in relation to prevailing temperature irrespective of fish size. In this way, a direct comparison between observed and maximum possible growth could be made for the whole season, disposing of the limitations of the growth model of Fonds et al. (1992). The fact that male and female growth differs, as has been described in detail for dab Limanda limanda by Lozán (1992), implies that maximum growth predictions had to be made for each sex.

The DEB model can mimic and predict the maximum growth experiments of Fonds et al. (1992). Experimental data represented observations on small groups of unknown mixtures of males and females. Hence, experimental data would be expected to fall in between the maximum prediction for both sexes. However, experimental data corresponded with maximum predictions for males, most likely because experimental observations represent mean values of small groups of fish compared with a DEB prediction of theoretical maximum growth.

The comparison of observed with model-predicted maximum growth showed that growth was generally 
not maximal irrespective of the season and that the difference even increased until July. These results slightly differ from the analysis by Teal et al. (2008) where growth rates in spring were found to be close to experimental growth rates. These differences reflect the use of different models: the mean observed growth of a group of fish that performed well (Fonds et al. 1992) versus maximum possible growth of an individual fish (DEB predictions).

A more detailed look into the growth analysis by Teal et al. (2008) suggests different periods with different patterns: first, a period of lower than possible growth until about the end of the period of larval immigration ( Day 125). Next, a second period until $\sim$ Day 180 with field growth rates in line with predicted maximum growth; hereafter, a period in summerautumn with lower growth rates than maximum predicted rates. The first period is characterized by a continuous immigration of settling larvae ranging in length from 10 to $15 \mathrm{~mm}$ (van der Veer 1986). As a consequence, mean growth estimates during this period will be underestimated. Just-settled plaice pass through a period of predation by shrimps until the population has reached a size of $3 \mathrm{~cm}$ (van der Veer \& Bergman 1987). This predation is size-selective and stronger on the lowest size classes (van der Veer \& Bergman 1987, van der Veer et al. 1997). Therefore, in the second period, length growth estimates may be slightly biased and overestimated. After this period, growth estimates appear to be lower than maximum possible growth. The observations of this study, after accounting for these sampling biases by restricting the analysis to the period after peak settlement, are in line with the findings of Teal et al. (2008): more or less maximum growth just after settlement, followed by a continuous reduction in growth performance until stabilization at $\sim 40 \%$ of the maximum possible growth from the end of July onwards.

The results of the present study eliminate experimental bias as a cause of the observed patterns and confirm the view of Kuipers \& Dapper (1984), Pihl (1985) and Teal et al. (2008) of food competition among epibenthic species in summer. Which other species are involved is unclear at present; however, other flatfish species are less likely than crustaceans and gobiids, which occur in much higher numbers. The underlying mechanisms of the competition for food might be related to interference affecting prey searching, capturing and handling, and reducing and limiting food intake. In this respect it is of interest that the difference between field and maximum predicted growth stabilized after July ( Day 225) for plaice $>8 \mathrm{~cm}$ : at a size of $\sim 8 \mathrm{~cm}$, plaice shifts from small bivalve siphons to larger, more energy containing tail tips as main food items (Kuipers 1977, De Vlas 1979). This is in line with the observations on the feeding behaviour of young plaice, which seems to depend particularly on the nature and density of available prey (Gibson 1980). It indicates that food quality is also of importance: shifts in prey species composition from small siphon tips to Arenicola tail tips affect plaice growth performance.

\section{Long-term trends in nursery ground quality}

Based on the assumption that food was already limiting for 0-group plaice in summer, Teal et al. (2008) argued that a further increase in seawater temperature may negatively affect the nursery quality if the production rate of benthic food cannot meet the increase in energy requirements of 0 -group plaice. However, instead of food conditions, prevailing temperature might be more important. The high temperature sensitivity of plaice makes it relatively vulnerable to temperature changes and hence climate change (Freitas et al. 2007). The key factor for plaice might be its relatively low upper tolerance limit: under experimental conditions, growth starts to decrease at $\sim 20^{\circ} \mathrm{C}$ (Fonds et al. 1992). In recent years, I- and II-group plaice have disappeared from the intertidal (H. W. van der Veer \& J. IJ. Witte pers. obs.) and moved to deeper waters (van Keeken et al. 2007). Also, 0-group plaice disappears from the intertidal area in late summer $(\mathrm{H}$. W. van der Veer \& J. IJ. Witte pers. obs.), which is much earlier than in the past (Kuipers 1977). Therefore, a further increase in water temperature might imply that temperate estuaries such as the Wadden Sea may become unsuitable as nursery areas for plaice from a physiological point of view, irrespective of prevailing food conditions. Whether this also holds true for the other epibenthic species remains unclear. However, it might be of interest to find out whether and to what extent competition for food occurs in the other epibenthic species.

Acknowledgements. Thanks are due to E. Adriaans, skipper of RV 'Stern' and to our colleagues in assisting during sampling. This study was partly funded through the FP6 project RECLAIM (Contract no. 044133 - FISH REG/A3(2006)D/ 14751).

\section{LITERATURE CITED}

Amara R (2003) Seasonal ichthyodiversity and growth patterns of juvenile flatfish on a nursery ground in the Southern Bight of the North Sea (France). Environ Biol Fishes 67:191-201

Amara R, Paul C (2003) Seasonal patterns in the fish and epibenthic crustaceans community of an intertidal zone with particular reference to the population dynamics of plaice and brown shrimp. Estuar Coast Shelf Sci 56: 807-818

Ansell AD, Comely CA, Robb L (1999) Distribution, move- 
ments and diet of macrocrustaceans on a Scottish sandy beach with particular reference to predation on juvenile fishes. Mar Ecol Prog Ser 176:115-130

Berghahn R, Lüdemann K, Ruth M (1995) Differences in individual growth of newly settled 0-group plaice (Pleuronectes platessa L.) in the intertidal of neighbouring Wadden Sea areas. Neth J Sea Res 34:131-138

Bergman MJN, van der Veer HW, Zijlstra JJ (1988) Plaice nurseries: effects on recruitment. J Fish Biol 33:201-218

Bolle LJ, Dapper R, Witte JIJ, van der Veer HW (1994) Nursery grounds of dab (Limanda limanda L.) in the southern North Sea. Neth J Sea Res 32:299-307

Dapper R (1978) De Balgzand scholgegevens 1975, 1976, 1977. Neth J Sea Res Int Rep 1978 12:1-53

> De Vlas J (1979) Annual food intake by plaice and flounder in a tidal flat area in the Dutch Wadden Sea, with special reference to consumption of regenerating parts of macrobenthic prey. Neth J Sea Res 13:117-153

Fonds M, Cronie R, Vethaak AD, van der Puyl P (1992) Metabolism, food consumption and growth of plaice (Pleuronectes platessa) and flounder (Platichthys flesus) in relation to fish size and temperature. Neth J Sea Res 29:127-143

> Freitas V, Campos J, Fonds M, van der Veer HW (2007) Potential impact of climate change on epibenthic predatorbivalve prey interactions in temperate estuaries. J Therm Biol 32:328-340

Freitas V, Campos J, Skreslet S, van der Veer HW (2010a) Habitat quality of a sub-arctic nursery ground for 0-group plaice (Pleuronectes platessa L.). J Sea Res 64:26-33

Freitas V, Cardoso JFMF, Lika K, Peck MA, Campos J, Kooijman SALM, van der Veer HW (2010b) Analysis of physiological performance of North Atlantic marine organisms by means of interspecies differences in DEB parameters. Phil Trans Royal Soc doi:10.1098/rstb.2010.0049

Gibson RN (1980) A quantitative description of the behaviour of wild juvenile plaice (Pleuronectes platessa L.). Anim Behav 28:1202-1216

Goodall DW (1983) Estuaries and enclosed seas. Ecosystems of the world, Vol 26. Elsevier, Amsterdam

Haedrich RL (1983) Estuarine fishes. In: Ketchum BH (ed) Estuaries and enclosed Seas. Elsevier Scientific, New York, NY, p 183-207

Jager Z, Kleef HL, Tydeman P (1995) Mortality and growth of 0-group flatfish in the brackish Dollard (Ems Estuary, Wadden Sea). Neth J Sea Res 34:119-129

> Jensen KT, Jensen JN (1985) The importance of some epibenthic predators on the density of juvenile benthic macrofauna in the Danish Wadden Sea. J Exp Mar Biol Ecol 89:157-174

Karakiri M, Berghahn R, van der Veer HW (1991) Variations in settlement and growth of 0-group plaice (Pleuronectes platessa L.) in the Dutch Wadden Sea as determined by otolith microstructure analysis. Neth J Sea Res 27: 345-351

Kiorbøe T (1978) Feeding rate in juvenile flounder in relation to prey density. Kiel Meeresforsch, Sonderh 4:275-281

Kooijman SALM (2010) Dynamic energy budget theory for metabolic organization, 3rd edn (revised). Cambridge Univ Press, Cambridge

Kühl H, Kuipers BR (1983) Qualitative food relationships of Wadden Sea fishes. In: Dankers N, Wolff WJ, Zijlstra JJ (eds) Fishes and fisheries of the Wadden Sea. Balkema Press, Rotterdam, p 112-123

Kuipers B (1975) On the efficiency of a two-meter beam trawl for juvenile plaice (Pleuronectes platessa). Neth J Sea Res 9:69-85

Kuipers BR (1977) On the ecology of juvenile plaice on a tidal flat in the Wadden Sea. Neth J Sea Res 11:56-91
Kuipers BR, Dapper R (1981) Production of Crangon crangon in the intertidal zone of the Dutch Wadden Sea. Neth J Sea Res 15:33-53

Kuipers BR, Dapper R (1984) Nursery function of the Wadden Sea tidal flats for the brown shrimp Crangon crangon. Mar Ecol Prog Ser 17:171-181

> Lozán JL (1992) Sexual differences in food intake, digestive tract size and growth performance of the dab Limanda limanda L. Neth J Sea Res 29:223-227

Mattila J, Bonsdorff E (1998) Predation by juvenile flounder (Platichthys flesus L.): a test of prey vulnerability, predator preference, switching behaviour and functional response. J Exp Mar Biol Ecol 227:221-236

> Modin J, Pihl L (1994) Differences in growth and mortality of juvenile plaice, Pleuronectes platessa L., following normal and extremely high settlement. Neth J Sea Res 32: 331-341

> Nash RDM, Geffen AJ, Hughes G (1994) Individual growth of juvenile plaice on an Irish Sea nursery ground (Port Erin Bay, Isle of Man). Neth J Sea Res 32:369-378

Pihl L (1985) Food selection and consumption of mobile epibenthic fauna in shallow marine areas. Mar Ecol Prog Ser 22:169-179

Pinheiro J, Bates D (2000) Mixed effects models in S and S-Plus. Springer-Verlag, New York, NY

Pinheiro J, Bates D, DebRoy S, Sarkar D, the R Core team (2009) nlme: linear and nonlinear mixed effects models. R package version 3.1-96

R Development Core Team (2009) R: a language and environment for statistical computing. R Foundation for Statistical Computing, Vienna. Available at www.R-project.org

> Rijnsdorp AD, van Leeuwen PI (1992) Density-dependent and density-independent changes in somatic growth of female plaice Pleuronectes platessa between 1930 and 1985 as revealed by back-calculation of otoliths. Mar Ecol Prog Ser 88:19-32

Riley JD, Corlett J (1966) The numbers of 0-group plaice in Port Erin Bay, 1964-1966. Rep Mar Biol Stn Port Erin 78 1965:51-56

Ross AH, Nisbet RM (1990) Dynamic models of growth and reproduction of the mussel Mytilus edulis L. Funct Ecol 4: 777-787

Teal LR, De Leeuw JJ, Rijnsdorp AD, van der Veer HW (2008) Effects of climate change on growth of 0-group sole and plaice. Mar Ecol Prog Ser 358:219-230

van Aken HM (2003) 140 years of daily observations in a tidal inlet (Marsdiep). ICES Mar Sci Symp 219:359-361

van Beek FA (1976) Aantallen, groei en voedselopname van de zandgrondel en de wadgrondel op het Balgzand. Neth Inst Sea Res Int Rep 1976 9:56

van der Veer HW (1986) Immigration, settlement, and density-dependent mortality of a larval and early postlarval 0 -group plaice (Pleuronectes platessa) population in the western Wadden Sea. Mar Ecol Prog Ser 29:223-236

> van der Veer HW, Bergman MJN (1987) Predation by crustaceans on a newly settled 0 -group plaice Pleuronectes platessa population in the western Wadden Sea. Mar Ecol Prog Ser 35:203-215

van der Veer HW, Witte JIJ (1993) The 'maximum growth/ optimal food condition' hypothesis: a test for 0-group plaice Pleuronectes platessa in the Dutch Wadden Sea. Mar Ecol Prog Ser 101:81-90

van der Veer HW, Witte JIJ (1999) Year-class strength of plaice Pleuronectes platessa L. in the Southern Bight of the North Sea: a validation and analysis of the inverse relationship with winter seawater temperature. Mar Ecol Prog Ser 184:245-257 
van der Veer HW, Pihl L, Bergman MJN (1990) Recruitment mechanisms in North Sea plaice Pleuronectes platessa. Mar Ecol Prog Ser 64:1-12

van der Veer HW, Bergman MJN, Dapper R, Witte JIJ (1991) Population dynamics of an intertidal 0-group flounder Platichthys flesus population in the western Dutch Wadden Sea. Mar Ecol Prog Ser 73:141-148

van der Veer HW, Ellis T, Miller JM, Pihl L, Rijnsdorp AD (1997) Size-selective predation on juvenile North Sea flatfish and possible implications for recruitment. In: Chambers RC, Trippel EA (eds) Early life history and recruitment in fish populations. Chapman Hall, London, p 279-303

> van der Veer HW, Geffen AJ, Witte JIJ (2000) Exceptionally strong year classes in plaice Pleuronectes platessa: Are they generated during the pelagic stage only, or also in the juvenile stage? Mar Ecol Prog Ser 199:255-262

van der Veer HW, Kooijman SALM, van der Meer J (2001a) Intra- and interspecies comparison of energy flow in North Atlantic flatfish species by means of dynamic energy budgets. J Sea Res 45:303-320

van der Veer HW, Dapper R, Witte JIJ (2001b) The nursery function of the intertidal areas in the western Wadden Sea for 0-group sole Solea solea (L.). J Sea Res 45:271-279

van der Veer HW, Cardoso JFMF, van der Meer J (2006) Estimation of DEB parameters for various North Atlantic bivalve species. J Sea Res 56:107-124

van der Veer HW, Cardoso JFMF, Peck MA, Kooijman SALM

Editorial responsibility: Stylianos Somarakis,

Heraklion, Greece
(2009) Physiological performance of plaice Pleuronectes platessa (L.): a comparison of static and dynamic energy budgets. J Sea Res 62:83-92

van Haren RJF (1995) Application of dynamic energy budgets to xenobiotic kinetics in Mytilus edulis and population dynamics of Globodera pallida. PhD thesis, Vrije Universiteit, Amsterdam

van Keeken OA, van Hoppe M, Grift RE, Rijnsdorp AD (2007) Changes in the spatial distribution of North Sea plaice (Pleuronectes platessa) and implications for fisheries management. J Sea Res 57:187-197

Wolff WJ (1983) Ecology of the Wadden Sea. Balkema Press, Rotterdam

Wood SN (2006) Generalized additive models: an introduction with R. Chapman \& Hall/CRC, Boca Raton, FL

Zijlstra JJ (1972) On the importance of the Wadden Sea as a nursery area in relation to the conservation of the southern North Sea fishery resources. Symp Zool Soc London 29: $233-258$

Zijlstra JJ, Witte JIJ, Dapper R (1982) Settlement, growth and mortality of post-larval plaice (Pleuronectes platessa) in the western Wadden Sea. Neth J Sea Res 15:250-272

Zuur AF, Ieno EN, Walker N, Saveliev AA, Smith GM (2009) Mixed effects models and extensions in ecology with R. Springer-Verlag, Berlin

Zuur AF, Ieno EN, Elphick CS (2010) A protocol for data exploration to avoid common statistical problems. Methods Ecol Evol 1:3-14

Submitted: May 10, 2010; Accepted: August 24, 2010

Proofs received from author(s): October 1, 2010 